\title{
Children's engagement with educational iPad apps: Insights from a Spanish classroom
}

\author{
Natalia Kucirkova, David Messer a, Kieron Sheehy (a)
}

a The Open University, Walton Hall, Milton Keynes, MK6 7AA, England, UK

Carmen Fernández Panadero (b)

b Dep. Ingeniería Telemática, Universidad Carlos III de Madrid, Spain

\begin{abstract}
This study investigates the effects of a story-making app called Our Story and a selection of other educational apps on the learning engagement of forty-one Spanish 4-5-year-olds. Children were observed interacting in small groups with the story-making app and this was compared to their engagement with a selection of construction and drawing apps. Children's engagement was analysed in two ways: it was categorised using Bangert-Drowns and Pyke's taxonomy for individual hands-on engagement with educational software, and using the concept of exploratory talk as developed by Mercer et al. to analyse peer engagement. For both approaches, quantitative and qualitative indices of children's engagement were considered. The overall findings suggested that in terms of the Bangert-Drowns and Pyke taxonomy, the quality of children's individual engagement was higher with the OS app in contrast to their engagement with other app software. The frequency of children's use of exploratory talk was similar with the OS and colouring and drawing apps, and a detailed qualitative analysis of the interaction transcripts revealed several instances of the OS and drawing apps supporting joint problem-solving and collaborative engagement. We suggest that critical indices of an app's educational value are the extent to which the app supports opportunities for open-ended content and children's independent use of increasingly difficult features.
\end{abstract}

\section{Introduction}

\section{1. iPads and early literacy research}

Since their first release in spring 2010, iPads and their applications (apps) have become popular worldwide with a broad range of users, including young pre-school children (Costello, 2012). Yet to date, there is little empirical research that addresses the educational value and impact of iPad apps which are advertised as 'educational'. Research investigating children's use of similar tools is emerging, with for example, Billings \& Mathison's study (2012) investigating the use of iPods by 4th grade English learners or Parish-Morris, Mahajan, Hirsh-Pasek, Golinkoff, and Collins (2013) comparing the benefits of batteryoperated, touch-sensitive children's electronic console books and traditional books. Findings from these studies are informative but not directly transferable to iPads as these have different affordances than iPods or electronic books, with the former mainly used for keeping records, playing and storing audio-visual media, and electronic books used for the same purposes as print books. The use of iPads as a new tool in their own right has been studied but primarily with a focus on older children and adolescents (e.g., Manuguerra \& Petocz, 2011). With the exception of two studies (Falloon, 2013; Osmon, 2011), work on young children's iPad use has been focussed on the communication and social op-portunities of children with special educational needs (Hager, 2010; McClanahan, Williams, Kennedy, \& Tate, 2012) or it has employed a primarily exploratory, rather than explanatory, approach of investigation (Hutchison, Beschorner, \& Schmidt-Crawford, 2012; Kucirkova, Messer, Sheehy, \& Flewitt, 2013). Falloon's (2013) 
recent study has investigated the design and content features of selected iPad apps in relation to the learning pathways of five-year-olds, and concluded that researchers and developers need to work together to improve the educational value of children's iPad apps. We agree with this premise, particularly in light of the wide availability and popularity of iPads among young children, their use in many Western pre-schools (Butkus, 2012), and the on-going call for educators to 'more fully integrate technology into the curriculum to encourage the active engagement and thinking of young children' (Couse \& Chen, 2010, p.76). As of January 2013, there were more than 775,000 apps available (Pure Oxygen Labs, 2013) and apps categorised as educational form the second top category for downloads (Statista, 2013). Apps for toddlers and preschool children are particularly popular in terms of both the variety created and the number of downloads (Shuler, 2012). With our colleagues at The Open University, we co-designed a children's app for supporting children's learning through the activity of story-creation and story-sharing. In this paper, we consider the app's educational value for young pre-schoolers.

\subsection{Educational value of iPad apps for young children}

Despite its wide use in research and practice, the term "educational value" is a contested and contextdependent concept, essentially justified as a value judgement (Walker, 1982/1983). Accordingly, researchers attempting to establish the educational value of iPad apps face the same challenges identified in research concerned with the educational effectiveness of computer-based software programs, such as contextual variance of the software use and implementation, and the multitude and kinds of educational software available (Stamelos et al., 2000). With iPad apps, an evaluation of educational value is especially difficult because of the abundance of apps advertised as 'educational' on both the Apple and Googleplay market, and the apps' worldwide deployment in various kinds of pre-school environments (Levine, 2012). Aware of these difficulties, we aimed to empirically investigate young children's active engagement with the software and with their peers when using a selection of iPad apps and in this way, gain an insight in their educational value.

\subsection{The present study}

We set out to investigate the effects of a specific iPad app, called Our Story (OS hereafter), purposefully designed to support young children's engagement in story-making activities. The OS app is available as a free public download in the Apple and Googlemarket apps store (educational category) and its main features and a list of suggested activities are described on a website for users (http://creet.open.ac. uk/projects/ourstory/). In addition to the OS app, we analysed children's engagement with other iPad apps that were selected by the teachers for use in the classroom. We anticipated that comparing the OS app with other educational apps will offer insights into effects specific to the OS app and provide us with more information on the kind of task and contents it supports. This follows Jacques (1995) and the notion that software content, features, and the learning task are important influential factors in children's engagement with a piece of software.

\subsubsection{Measuring children's engagement with educational technology}

We aimed to analyse children's engagement by adopting a comprehensive set of measures of children's engagement which would encompass behavioural, intellectual, and emotional aspects in a learning situation. This fits the theoretical engagement model developed by Guthrie and Wigfield (2000) for children's reading comprehension and Bangert-Drowns \& Pyke's taxonomy developed for children's engagement with 
educational software. Bangert-Drowns and Pyke (2001) studied elementary school children (pre-K through sixth grade) in an urban school using specific computer-based multimedia educational software and categorised students' engagement in terms of its complexity and its relationships with intrinsic motivation, volition, and self-regulated learning. This led the authors to the development of a seven-level taxonomy, which has been validated as a tool for analysing aspects of students' engagement with computer software in various learning environments (e.g., Lim, 2008; Lynch, Kuipers, Pyke, \& Szesze, 2005).

In addition to Bangert-Drowns and Pyke's taxonomy, we aimed to characterise children's engagement in relation to their collaborative talk, especially because some iPad apps are designed to support both individual and collaborative engagement (including the OS app). In effective learning environments, children engage in collaboration and learn from each other (Mercer, 1996) and this is crucial for their social and cognitive development (Edwards \& D'arcy, 2004; Tao, 1999). Children's collaborative engagement usually is best studied through peer talk, which has 'unique affordances for promoting language development' (Blum-Kulka \& Snow, 2004, p.293). Mercer et al. have investigated in detail children's engagement in computer-based joint activities in the SLANT project (Dawes, Fisher, \& Mercer, 1992; Wegerif, Mercer, \& Dawes, 1999), and developed a taxonomy of three mutually exclusive categories of peer talk in classroom : disputational, cumulative and exploratory. Exploratory talk is characterised by the use of justifications, suggestions for alternatives or compromise, and children's use of this type of talk is associated with positive educational outcomes including performance on reasoning tasks (problem solving), thinking and school achievement (Mercer, 2000; Mercer, Dawes, \& Staarman, 2009; Rojas-Drummond \& Mercer, 2003). Our analyses therefore focussed on this form of collaborative talk only. Research examining the collaborative engagement of younger (pre-school) children has shown that some activities support this type of talk more than others (Howe \& Mercer, 2007) and this raises the question of whether different iPad apps and the activities they mediate, facilitate exploratory talk to different extents.

We aimed to contribute to the research concerning young children's learning with iPad apps and explore in more detail the kinds of engagement these tools facilitate. In particular, we compared the effects of different types of apps on children's individual and collaborative interactions, as assessed by both quantitative and qualitative indicators of engagement in learning. Our overarching aim was to provide

answers for practitioners and researchers interested in whether certain features or contents of iPad applications might increase children's engagement with an activity.

\section{Material and methods}

\subsection{Participants}

This study is part of a larger project which investigated the use of iPads and specific educational iPad apps in a Spanish school context. The participating school was a government-funded school in a Madrid suburb area, for children aged 3-15 years and attended by predominantly white, mono-lingual children, from a middle-class neighbourhood. In this study, we use data collected in two classrooms attended by forty-one children, 24 girls and 17 boys, aged between four and five years.

\subsection{Study procedure}


We followed the British Educational Research Association guidelines (BERA, 2011) and upon approval by the institutional ethics review committee, we loaned three iPad2s and two iPad1s to the early years department. The teachers who participated in the study were free to share them among their individual classrooms as they wished for the duration of the six-month project. In this paper, we focus on video observations made over three days in two early years classrooms, towards the end of the project when children had developed sufficient ease with the use of the technology.

As in other iPad initiatives in elementary schools (see Milman, Carlson-Bancroft \& Boogart, 2012), children in these two classrooms were allowed to use the iPad apps during free-choice time. Children were divided in groups of 2-5 children and were free to engage with the iPad as they wished in a dedicated corner of the room. In both classrooms, teachers used the iPads as an alternative resource for literacy and symbol-making activities. Children's fluency with iPads varied and not all children were familiar with touch-screen devices. The teachers did not interact with children during their "iPad time" and, similarly to children's use of other resources in the classroom, children could pick and choose whichever activity (and app supporting this activity) they wished. The apps were not sorted out in a particular order or cat-egories, so some apps were available on the beginning screen and some needed to be accessed through pageswiping.

The research data is from observations and video recordings made in two classrooms across three days, and selected segments where children were interacting with the OS app (context1), and the construction and colouring apps (context2). The researcher (first author of this study) showed the children participating in the study how the OS app worked on the first day of observations, but during all the following observations, the researcher provided minimal assistance or guidance with the manipulation of the individual apps or the activities they supported.

\subsection{The OS app: context1}

The OS app allows the creation of self-made digital audio-visual texts. Pictures and audio features can be created and added in the moment of story-creation by using the iPad's inbuilt camera and audio-recorder (e.g., by taking a picture of surrounding environment), or retrieved from a folder of saved pictures and audio files. In the Edit mode, users can customise or personalise their stories, by adding their own texts or sounds to each picture. There is no restriction on the kind of or amount of text added and there is also no limitation on the length of the audio-recording. Customised pictures can be grouped together to create a digital story, which can be displayed in a sequence in a similar way to a picture book. Finished stories can be either printed out or shared with other users wirelessly, however these features were not used and examined in this study. There are currently three versions of OS on the market, for android, smartphones and iPads. The version used in this study was a prototype of the iPad version, Fig. 1 shows the app's user-interface, which has a basic layout (a gallery of pictures on the top and a filmstrip for a story at the bottom of the app) and a child-friendly design (large iconic buttons).

\subsection{Other educational apps studied in the study: context2}

We aimed to compare children's use of OS with applications chosen by the teachers. It was intended that all participating teachers would download any apps they deemed appropriate for their pedagogical goals and learning activities in the classrooms. The teachers decided to delegate the task of apps' selection and iPad 
set-up to the head of the early years department who was IT-knowledgeable and keen to do so. This teacher put all the iPads under one account and downloaded over forty different apps from the educational category in the Apple store, including the OS app. In the present study, we focus on the most used apps in the two classrooms where we conducted our video obser-vations. These apps fell into two categories: construction/completion apps (e.g., Domino, Jigsaws 123 , Jigsaws.free (2x), Kids' puzzles ) and colouring/drawing apps (e.g., Pick n Colour, Vivid Paint free ).

\subsection{Data coding}

Two coding frameworks of children's engagement were used. To characterise children's individual hands-on engagement in the two contexts, we used Bangert-Drowns and Pyke's (2001) taxonomy, details of which are provided in Table 1.

This taxonomy was used to code children's engagement at intervals of five minutes which produced 5 time points for observation. This allowed us to compare the occurrence of specific types of engagement in context1 (OS app) and context2 (drawing and construction apps). In addition, we used Bangert-Drowns and Pyke's criteria to characterise typical engagement episodes qualitatively (see Table 1 for details), using the transcripts from context 1 and context 2 .

To analyse exploratory talk, we adapted the quantitative coding method used by Mercer, Wegeriff \& Dawes (1999) and Littleton et al. (2005), and focused on keywords that have been identified as indicative of exploratory talk. In line with previous research, the unit of analysis was word rather than utterance (Schmitz $\&$ Winskel, 2008) and we coded 15 keywords in context. The keywords were adapted from Schmitz and Winskel (2008) and included:

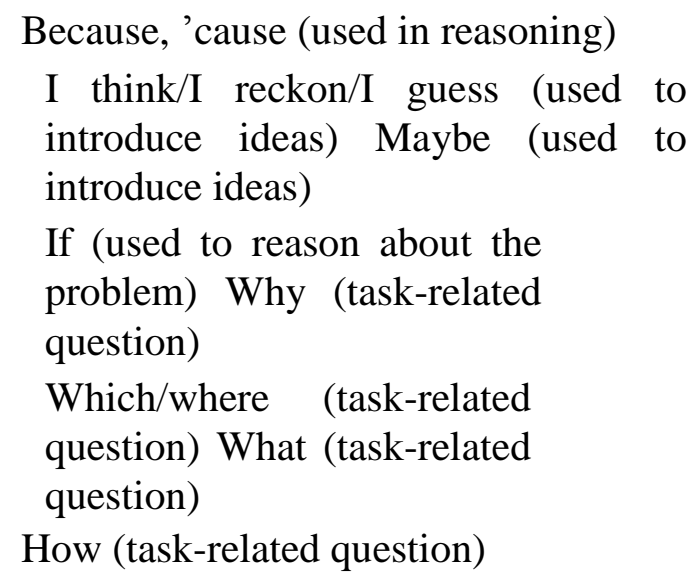




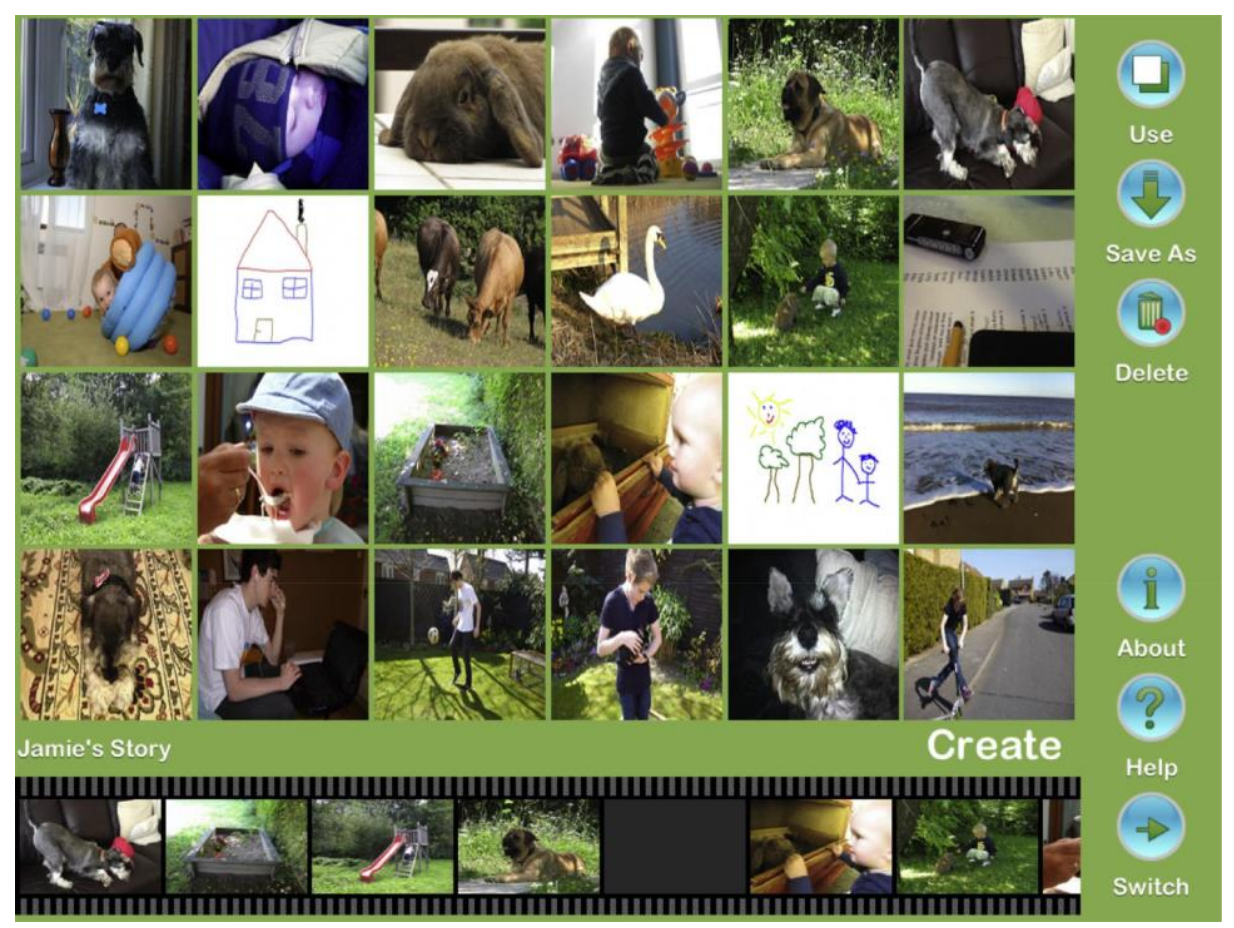

Fig. 1. The OS app user-interface.

You (used in a question)

Actually (used to justify/clarify)

But (used for constructive challenging or

clarification) No (used with justification

or reasoning)

Let's (suggestion of cooperation, excluding 'let's see' as

a generalization).

Would

Could

\subsection{Analysis procedure}

There was $14.5 \mathrm{~h}$ of video data and for the present analysis, shorter video segments were selected. The selection process involved two phases. In phase1, we selected segments that included several groups of 3-5, children, interacting with both the OS (context1) and construction or drawing apps (context2). We endeavoured to include all participating children from both classrooms but had to compromise between including all children and keeping wherever possible the same groups of children interacting in both contexts. Children were grouped together by the teacher but did not always adhere to their group allocation and we excluded instances where children joined a group only briefly or randomly. We also excluded data which were of low quality (e.g., unidentifiable sound or strong illumination variations which occluded the user interface of particular apps). This selection process resulted into video segments of $77 \mathrm{~min} 42 \mathrm{~s}$ for children's interactions in context 1 , and $28 \min 34 \mathrm{~s}$ for context 2 . These selected segments were transcribed and translated from Spanish to English. In phase2, we identified $25 \mathrm{~min}$ of talk for analysis in each of the two contexts. To ensure that these 25 min serve as a representative example of children's engagement in 
both contexts, the $25 \mathrm{~min}$ in context 1 were composed of three shorter segments of $8.3 \mathrm{~min}$ from the beginning, middle and end of the original $77 \mathrm{~min}$ and for context2, we excluded a total of $1 \mathrm{~min} 11 \mathrm{~s}$ from the beginning, middle and end of the 28 min and 34 s segment. Subsequently, we time-sampled children's activities in the two contexts at 5-min intervals and noted the kind of engagement (as per Bangert-Drowns and Pyke's taxonomy) at each of the five intervals in each of the two contexts. We also counted the number of keywords indicative of exploratory talk as they occurred in the

Table 1

The Levels identified in Bangert-Drowns \& Pyke's taxonomy (adapted from Bangert-Drowns \& Pyke, 2001).

\begin{tabular}{|c|c|}
\hline $\begin{array}{l}\text { Level } \\
1\end{array}$ & Literate thinki \\
\hline $\begin{array}{l}\text { Level } \\
2\end{array}$ & $\begin{array}{l}\text { Critical } \\
\text { engagement }\end{array}$ \\
\hline $\begin{array}{l}\text { Level } \\
3\end{array}$ & $\begin{array}{l}\text { Self-regulate } \\
\text { interest }\end{array}$ \\
\hline $\begin{array}{l}\text { Level } \\
4\end{array}$ & $\begin{array}{l}\text { Structure } \\
\text { dependent }\end{array}$ \\
\hline $\begin{array}{l}\text { Level } \\
5\end{array}$ & $\begin{array}{l}\text { engagement } \\
\text { Frustrated } \\
\text { engagement }\end{array}$ \\
\hline
\end{tabular}

Level Unsystematic

$6 \quad$ engagement

Level

$7 \quad$ Disengagement
Student interprets software content from multiple and personally

meaningful perspectives. Student manipulates

software features to explore alternative interpretations as an opportunity to reflect on personal values or experiences.

Student investigates operational and content-related limitations of the software. Student manipulates software features

to test personal understandings or limitations of the software presentations.

Student creates personal goals within the software to make the software as

personally interesting as possible. Student

adjusts software features to sustain deeply involved, interesting, or

challenging interactions. Student adapts software for

personally defined purposes.

Student is sensitive to and competent with software operation and navigation. Student pursues goals communicated by

the software and responds to operational, navigational, or content

organization.

Student possesses clear goals when working with the software but is

unsuccessful in accomplishing them. Student

knows what the software can do, but cannot accomplish it. Student may manifest stress or frustration in negative

comments, confusion, aggression, erratic behavior, agitation, distress, or anxiety.

Student has unclear goals when working with the software. Student moves from one incomplete activity to another

without apparent reason. Student successfully completes simple tasks

within the software but does not link tasks for

higher-order goals.

Student avoids working with the software or discontinues use prematurely.

Student may tinker with software in a

seemingly purposeless and unresponsive way. Or, student may in fact turn away from the software or resist using it at all.

25 min of each of the two contexts. For qualitative comparisons, we analysed the selected video extracts in their entirety. Fig. 2 provides an overview of our analysis procedure. 
Reliability was checked by a bilingual Spanish-English second coder, who checked the quantitative coding and qualitative categorisation on $20 \%$ of the transcription, with $94 \%$ agreement (Cohen's k $1 / 40.72$ ) for the quantitative coding and $92.6 \%$ for qualitative categorisation (Cohen's k 1/4 0.68).

\section{Results}

\subsection{Children's engagement according to Bangert-Drowns \& Pyke's taxonomy}

\subsubsection{Quantitative analysis}

Quantitative data analysis with the Bangert-Drowns \& Pyke taxonomy revealed that for context1, there were three different kinds of engagement in the five time points (see Table 2), while for context2, there was structure-dependent engagement at only one time point and unsystematic engagement at the remaining four time points. Table 2 summarises children's engagement according to Bangert-Drowns and Pyke taxonomy at the five time points.

\subsubsection{Qualitative analysis}

To provide more insight into children's engagement in the two contexts, we looked at children's interactions with the software, chil-dren's manipulation of the app, body posture and verbalisations and compared these with Bangert-Drown sand Pyke's descriptions of higher and lower levels of engagement with educational software. These analyses revealed that in context1, children showed signs of self-regulated interest (Level3) and also, critical engagement (Level 2), as they were evaluating and extending their knowledge of letters (by typing their own names in the app's text box) and developing digital expertise by trying out several features of the app, such as audio-recording of stories or insertion of images into stories. In context 2 , when children were using the colouring apps, they were selectively pressing on specific colours and colouring formats (e.g., pencil versus paint brush) and thus showing and developing their understanding of the

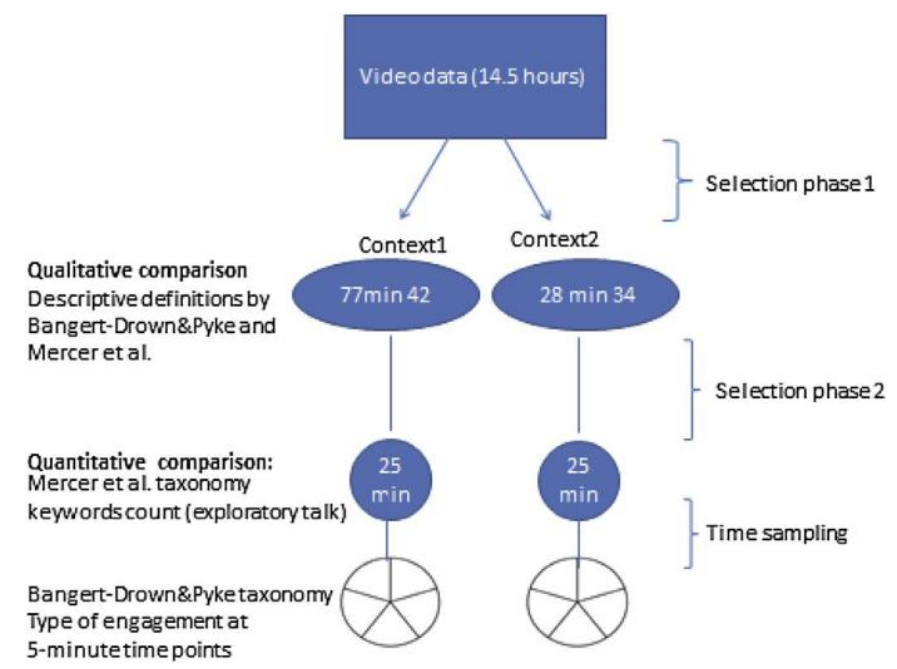

Fig. 2. The

analysis

procedure. 
Table 2

Children's individual hands-on engagement in Context 1 and Context 2 using Bangert-Drowns and Pyke taxonomy which was coded at 5-min intervals.

\begin{tabular}{|c|c|c|}
\hline Time point & Context1 (the OS app) & $\begin{array}{l}\text { Context } 2 \text { (drawing and } \\
\text { construction apps) }\end{array}$ \\
\hline 1 & Self-regulated engagement & $\begin{array}{l}\text { Unsystematic engagement } \\
\text { Structure-dependent }\end{array}$ \\
\hline 2 & $\begin{array}{l}\text { Critical engagement } \\
\text { Structure-dependent }\end{array}$ & engagement \\
\hline 3 & $\begin{array}{l}\text { engagement } \\
\text { Structure-dependent }\end{array}$ & Unsystematic engagement \\
\hline 4 & engagement & Unsystematic engagement \\
\hline 5 & Self-regulated engagement & Unsystematic engagement \\
\hline
\end{tabular}

possibilities of the digital interface and its content by creating "problems" or personal tasks to test the limitations and possibilities of the software (see Bangert-Drowns \& Pyke, 2001, p.224). With the colouring/drawing apps, there was thus evidence of more structure-dependant engagement (Level 4) which meant that children complied with the software's demand characteristics. In contrast, when completing an iPad puzzle, children were uncritically following what the software offered, i.e. did not search for more complex puzzle structures but rather proceeded until a few simple, usually two-pieces, puzzles were completed and they received an automated "well done" feedback from the app. As such, with the puzzles/construction apps, children were predominantly showing signs of unsystematic engagement (Level 6), as they were only interacting with the 'perceptible aspects of the software' and seemed to have limited awareness of the software structure (Bangert-Drowns \& Pyke, 2001, p.227).

We illustrate the contrasting engagement patterns in context 1 and context 2 with two extracts taken from the transcripts, both of an approximately similar length of one minute. In Extract1, taken from context1, children exchange ideas related to the functions of the software and the task of story-writing overall, which corresponds to self-regulated and critical engagement. In Extract2 from context2, there is evidence of structure-dependent and unsystematic engagement as children are mostly focused on who takes turn next and their engagement with the software corresponds to its immediate feedback capability (Table 3).

\subsection{Children's engagement with regard to the exploratory talk}

\subsubsection{Quantitative comparison}

In analysing children's collaborative and verbal engagement, we were first interested in the overall number of words spoken in the 25 min segments from each of the two contexts. In total, children produced 777 words in context 1 and 402 words in context2. Of these, there were 44 keywords indicative of exploratory talk when using the OS app (context1) and 15 keywords indicative of exploratory talk in context2. Taking into account the proportion of words spoken in both contexts, the difference between the two contexts was minimal, with approximately $6 \%$ of talk in context 1 characterised by exploratory talk and approximately $4 \%$ in context 2 .

\subsubsection{Qualitative comparison}


Next, we looked in detail at the situations when children used words indicative of exploratory talk. Based on the information in the transcripts we found that, in context2, all but two of the keywords involving exploratory talk occurred when children were using the drawing or colouring apps. The use of these apps seemed to encourage situations in which children used exploratory questions, offered relevant information for joint consideration, as well as situations when 'proposals may be challenged and counter-challenged, but if so reasons are given and alternatives are offered' (Mercer, 2000, p.98). The latter tendency is indicated by the below extract, in which we highlighted the exploratory keywords in italics.

\section{Extract3 (from context2)}

[two girls interacting with a colouring app]

G2: where do I delete, where do I delete?

[G2 shows G1 the deleting bottom on the screen and with her finger but when she presses, it doesn't work]

G2: hang on, how does it.delete.it's not deleting.try this if you want [pushes another button]

We can try this one. Look, now it's deleting! Can you see? [looks at G1]

The above patterns of peer talk were similar to children's peer talk in context1, when children were using the OS app. For example, when using this app, a girl typed first letter of her friend's name in small letters, but was immediately reminded by two other girls that this should be in capital letters. Such events led to joint problem solving situations, where children jointly searched for specific capital letters on a keyboard they were not all familiar with. Extract4 provides a snapshot of such interactions.

Extract4 (from context1)

[a boy and a girl using the OS app, keyboard feature to type a name]

B1: the O. where is the $\mathrm{O}$ ? [Girl shows the boy the letter $\mathrm{O}$ on the keyboard, boy taps on it]

B1: and then.then Rodolpho. The O. The O. where is the O? [both boy and girl look at the screen, visually searching for the $\mathrm{O}$ letter on the keyboard]

G1: let's see.you are left with.[turns the iPad to her and looks for letters. After a long search types the letter E]. you need a capital, right? let's keep this one. We need the capital letter.

B1: and the R [boy types R]. we need R in capital. Rodolpho. The O again. RodolphO. Rodolphooo. The

$\mathrm{O}$ again. There is $\mathrm{O}$ already. We need.[keeps on looking for letters]

Table 3

Children's engagement patterns in Context1 and Context2.

Bangert-Drown \&

Pyke's taxonomy

Context1

Girl2: P p p an a [typing the correct letters on the keyboard of the app]

Critical engagement

Girl3: Oh but you have to push here to give it a capital!

Self-regulated interest

Girl2: no! 
Boy1: yes!

Girl3: no, not this one! You have to delete it. because..because we have to put capital letters for beginning

Context2

[First $12 \mathrm{~s}$ two girls tapping several times on the screen with no words]

Unsystematic

Gir1: tap on this! Continues tapping, repeatedly on the screen]

engagement

Girl2: this one!

Girl1: and this!

[both girls continue tapping on the pictures for another $28 \mathrm{~s}$ ]

Girl1: let's see!

[Girl1 takes Girl2 \& Girl3's hands off the screen]

engagement

Girl1: just one!

Girl2: first it's your turn [points to Girl3] and then me! [points to herself]

[Girl3 starts tapping heavily on one puzzle piece]

Girl1: and then it's me!

Girl2: there! [points to Girl1 where to put the puzzle piece in the image]

G1: hang on, let me.hmm, there should go an R. [types a letter]

With both OS and the colouring/drawing apps, children's discussions evolved around joint problemsolving, as children were willing to find out how the apps operated and asked for help their peers or thought aloud as they searched for the features themselves, e.g., 'Where is the blue colour?' (context2) 'Where is the P letter?' (context1). When using these apps, children built on each other's sug-gestions and sought joint agreement in collaboration (c.f. Littleton et al., 2005). In contrast, we found less evidence for exploratory talk when looking in detail at children's talk with the construction apps in context2. Unlike the talk with the OS app, there was little evidence of critical evaluation or extending verbally what a child was doing with the app. Rather, children's talk was characterised by enthusiastic exclamations which parallelled the prerecorded app sounds, with no explicit comment about the nature of the activity, e.g., a child clapping or commenting with a loud "well done" when her peer completed an iPad puzzle. In addition, perhaps because of a lack of engagement in the activity of their peers, children were frequently discussing whose turn was next and negotiating the length of their turn with the iPad. Independent of the type of activity, occasional frustrations happened and conflicts arose when a child "jumped into" an activity already started by another child (e.g., a child tapping on the screen and thus disrupting the child's work). However, these situations were rare in both context 1 and context 2 .

\section{Discussion}

The aim of this study was to examine young children's engagement with specific iPad apps as a practical way of evaluating their educational value in a pre-school classroom. Our dual focus on children's collaborative verbal engagement with their peers as well as their hands-on individual engagement with the software allowed us to achieve insights into children's engagement with iPad app-mediated activities and evaluate these in light of the apps' features, content and learning task. Results of children's individual 
engagement with the apps, as determined by the Bangert-Drown \& Pyke taxonomy, showed that with the OS app, children meaningfully engaged with the software features as they searched for specific software functionalities and this maintained their intrinsic interest in the app. Time-sampling of interactions revealed that with this app, children's engagement varied, but did not go below level4 on Bangert-Drowns \& Pyke's 7-point scale, while for context2, children's engagement was by and large at level 2 (unsystematic engagement). Analysis of children's exploratory talk revealed that on average, children engaged in similar amounts of exploratory talk when using the OS app and the other selected iPad apps. However, a qualitative analysis revealed that in context 2 , children's use of exploratory talk occurred primarily when children used the colouring and drawing apps. Children's engagement with these apps was similar to that with the OS app, which was characterised by collaborative reasoning, thinking aloud and joint problem-solving.

In the next three sections, we consider the findings, in particular those relating to the OS app, in terms of the three aspects of Jacques' (1995) explanatory framework for children's engagement with software: the learning task, content and features supported by individual apps.

\subsection{Children's engagement and the learning task}

There is evidence that older children (9-11 years) participate in collaborative engagement through creating multimodal stories on computers (Rojas-Drummond, Albarrán, \& Littleton, 2008). Our findings concur with this, albeit with younger children whose collaborative engagement was evidenced in their joint creation of individual elements of a multimodal story (e.g., recording sounds for a specific picture). Similar to our findings, Rojas et al. (2008) found evidence of 'joint planning; taking turns; asking for and providing opinions; sharing, chaining and integrating of ideas; arguing their points of view; negotiating and coordinating perspectives; adding, revising, reformulating and elaborating on the information under discussion and seeking of agreements' (p.21). This similarly might be attributed to the learning task, i.e. multimodal story-making rather than the technology used to support it ( $\mathrm{PC}$ and iPad respectively). Also, the development of exploratory talk and collaborative engagement, have previously been facilitated over time through story making with computers and young children (5-6 years), with an evolution from cumulative to exploratory talk as children become more familiar with new technology (Hyun and Davis, 2005). In our study, the data were collected after the children had been using the apps for six months and so the effect of fa-miliarity may have been a factor in relation to individual apps, rather than the technology per se.

Another factor relates to the extent to which the apps in context 1 and context 2 explicitly mediated learning tasks focused on problem-solving. Previous research has established a relationship between exploratory talk and group problem solving (e.g., Wegerif \& Mercer, 1996). It is not clear why the children in our study engaged in more exploratory talk when jointly solving the task of drawing a picture or composing a story than completing a puzzle or jigsaw with the iPad, but we suspect that it might be attributed to the openness of the different tasks. Namely, while for the completion of puzzles or jigsaws there is one correct answer, when drawing a picture or making a story, several 'solutions' of the problem are possible. Thus, we speculate that the open-endedness of the story-creation and drawing tasks might have been the reasons for children's higher levels of engagement in both context1 and context2. Next, we consider the possible influence of the apps' features to gain more insight into the specificities of children's engagement in the two contexts.

\subsection{Children's engagement and the app features}


It is likely that overall, the intuitive and easy manipulation of iPads (Hutchison et al., 2012) largely facilitated children's collaborative talk rather than focus on how the tool operates. In addition, however, the individual apps used had specific features which may have played a role in children's predominantly unsystematic engagement in context 2 and more self-regulated and critical engagement in context1. In context1, specific features of the OS app such as its iconic and intuitive navigation may have facilitated children's independent use. Also, with the OS app, children were able to switch on the audio-recording button, start and stop the recording at appropriate time; select a picture they liked from an array of digital pictures in the iPad photo-album and type specific letters using the on-screen keyboard. Children also selectively used the text-feature to accompany the pictures they selected for annotation. However, although the app afforded inde-pendent use in terms of its operation, children asked for other children's help when it came to finding out how a specific feature worked. Rather than leaving the app and switching to another app on the iPad, children were keen to finish the task of e.g., typing their name and finding where the space bar was. This may have encouraged more structure-dependent engagement, arising to self-regulated engagement in which children create 'personal goals within the software to make the software as personally interesting as possible' (Bangert-Drowns \& Pyke, 2001, p. 221).

Similarly, in context2, all apps carried child-friendly features and were designed to support children's agency and independent use (such as for example choosing various colours or tools for drawing in the colouring apps). This may have been the reason for the instances of structure-dependent engagement we saw. However, although children seemed to be quick and confident in using the apps, the frequent occurrence of unsystematic engagement suggests that children were unclear about how to operate the various features embedded in these apps (e.g., higher levels of puzzles or more complex drawings) but did not seek their friends' advice or persisted in finding this out. Our findings thus further underscore the importance of apps having features which are easy to use, but also scaffold children's learning and in doing so, do not undermine children's creativity (Di Blas, Garzotto, Paolini \& Sabiescu, 2009).

\subsection{Children's engagement and the app content}

With the OS app, children were free to add any picture (from the gallery of pictures available), sounds or text they wished or were capable of. In contrast to the puzzle-making or jigsaw constructing apps (which have a pre-defined goal and end-product and as such, demand compliance with the software characteristics; see structure-dependent engagement, Bangert-Drowns \& Pyke, 2001), with the OS app, children were designers of their own story contents. This might have been the reason for why children sought approval from their peers on the content they created with the app and produced overall more talk in context 1 than context2. Given that the app itself has no inbuilt reward system or established criteria for success, children needed to talk to each other to verify their understandings (cf Mercer, 2000). Consequently, children in our study were less focused on the actual features of the OS software but rather relied on the skills and knowledge of their peers, as reflected in the greater number of words spoken overall and exploratory keywords in particular. The OS app could be therefore considered to support a more collaborative engagement than apps with bounded, or specified, success criteria. This hypothesis is supported by the finding that when the children were using the colouring and drawing apps, where the content and structure of the task is more open-ended than with puzzles (i.e. children can draw whatever they like in a preestablished space), they were displaying similar engagement levels to those with the OS app. 


\subsection{Study limitations and future research}

This study focused on children's natural engagement patterns and peer dynamics in a classroom environment. Our selected sample represents a snapshot of children's engagement in a dynamic and complex context and should be seen as a first step toward understanding children's learning engagement with iPad apps. The observation of naturally occurring interactions meant that children's access to apps was spontaneous and unrestrained. In particular, children's engagement with the iPad was not consistent in terms of time length, equal numbers of children participating and time spent with individual apps. In addition, certain apps that children self-selected had not been updated since the time teachers had downloaded them and consequently, did not perform as intended by the designers. We did not have data on the duration or frequency of engagement of individual children with individual apps and therefore caution against interpreting our findings in relation to other aspects of children's engagement, such as time spent on task or persistence (see Couse \& Chen, 2010) or intrinsic motivation and proactive engagement in pursuing self-selected goals (Deci \& Ryan, 1985). Nevertheless, our approach has strong ecological validity and practical relevance to pre-school settings, where children's engagement with several resources during free play is often uncontrolled and spontaneous, reflected in children's selection of apps in the present study. It is worth emphasising that in our observations, children were not guided by the teacher in the iPad-related activities, and it is an encouraging finding that children engaged in exploratory reasoning and higher-level of software engagement without such guidance. This is particularly important given the well-established link between exploratory talk and children's problem-solving and reasoning skills (e.g., Webb \& Treagust, 2006), and higher-levels of engagement with software and children's subsequent conceptual learning (Bangert-Drowns \& Pyke, 2001).

Falloon (2013) raised the concern of possible observer-effect in documenting children's iPad interactions through direct video recording, but he also detailed the technical difficulties and challenges involved in obtaining video data directly by the iPad. Cognisant of the limi-tations of both methods of video data collection, we opted for external video recording. Given that the project spanned a six-month-period (during which large amounts of data were collected), the children were used to the researcher's presence in the classroom and observing them in a variety of activities (with or without iPads). Furthermore, this study was an intra- rather than inter-media comparison, which further minimised the researcher's influence on children's behaviours during the observations. Although such a method does not provide data which would lend themselves to sophisticated coding procedures (cf Falloon, 2013), the data can be interpreted with well-established coding methods with which social processes of learning can be identified and analysed (Mercer, 2000) and thus serve comparison purposes. While we recognise that detailed transcripts and videoanalysis are unlikely to become a pragmatic evaluation tool for practitioners, we suggest that children's hands-on and verbal as well as individual and collaborative engagement are complementary, and could form the basis of future empirical evaluations of the educational value of iPad apps used in classrooms. Another future research avenue would be to analyse children's engagement over longer periods of time to compare, for example, how children's engagement might change at the beginning and end of a school year.

A key message to practitioners is that our findings complement and provide empirical support for the guidance on the educational value of apps provided on various online sites (e.g., Pai, 2012). Even though our study was not designed to compare the effects of open-ended versus forced-choice apps, in light of our findings, we can conclude that open-ended apps foster several desirable outcomes, including higher educational engagement and exploratory talk, which are associated with joint problem solving skills and academic success (see e.g., Mercer \& Dawes, 2001). Based on our findings, we support teachers' general 
preference for open-ended apps rather than those which focus on drill-and-practice activities (Harrold, 2012) and recommend that teachers focus on selecting apps that facilitate children's creativity and collaboration with peers. We also recommend that if practitioners choose to let children use iPad apps relatively unsupervised as it was the case in our study, they select apps which allow for independent use of basic but also incrementally difficult levels as children make progress. Acknowledging the limitations of our study, our results suggest that if iPad apps can support activities in which children participate at various levels of difficulty and also allow them to be self-expressive and creative, then these apps have the potential to be highly engaging and educationally powerful tools in a pre-school classroom.

\section{Conclusions}

In conclusion, the app features and app content can influence the extent to which children's engagement is of educational value. As with other technology-mediated learning tasks, the more an app supports easily accessible open-ended content accomplishments, the more likely it is that the activity will have positive educational impact. In light of the convergent evidence that children generally prefer a technology-mediated method than traditional method with paper and pencil for typical classroom activities such as drawing (Matthews \& Jessel, 1993; Matthews \& Seow, 2007; Couse \& Chen, 2010), this is an important message for educational professionals. Considering the large quantity of educational apps currently available for young children and the variety of learning activities these apps may support, we concur with Shuler's call (2012) that 'the time to start considering how to harness this media as a powerful educational tool is now' (p.7, Shuler, 2012).

\section{Acknowledgements}

We would like to thank all the teachers and students for their willingness to participate in the project. We gratefully acknowledge the contribution of Jose J. García Rueda and Raquel M. Crespo García from Dep. Ingeniería Telemática. Universidad Carlos III de Madrid.

The study was funded through a research grant to the first author of the study and through a Santander grant. The work was also partially funded by the EEE (Spanish Ministry of Science and Innovation, TIN2008-05163/TSI) and the eMadrid projects (Regional Government of Madrid, S2009/TIC-1650).

\section{References}

Bangert-Drowns, R. L., \& Pyke, C. (2001). A taxonomy of student engagement with educational software: an exploration of literate thinking with electronic text. Journal of Educational Computing Research, 24(3), 213-234. http://dx.doi.org/10.2190/0CKM-FKTR-0CPF-JLGR.

BERA. (2011). Ethical guidelines for educational research. London: British Educational Research Association. Available at http://www.bera.ac.uk/guidelines Accessed 08.05.12. Billings, E. S., \& Mathison, C. (2012). I get to use an iPod in school? Using technology-based advance organizers to support the academic success of English learners. Journal of

Science Education and Technology, (4), 494-503. http://dx.doi.org/10.1007/s10956-011-9341-0.

Blum-Kulka, S., \& Snow, C. E. (2004). Introduction: the potential of peer talk. Discourse Studies, 6(3), 291-306. http://dx.doi.org/10.1177/1461445604044290.

Butkus, H. (2012, June 9). A one-on-one ipad program in kindergarten!. Available at http://heidisongs.blogspot.com.es/2012/06/one-on-one-ipad-program-in-kindergarten. html Accessed 14.05.13. 
Costello, S. (2012). What are ipad sales all time?. Available at

http://ipod.about.com/od/ipadmodelsandterms/f/ipad-sales-to-date.htm Accessed May 14.05.13.

Couse, L. J., \& Chen, D. W. (2010). A tablet computer for young children? Exploring its viability for early childhood education. Journal of Research on Technology in Education, 43(1), 75-98.

Dawes, L., Fisher, E., \& Mercer, N. (1992). The quality of talk at the computer. Language and Learning, 22-25. Deci, E. L., \& Ryan, R. M. (1985). Intrinsic motivation and self-determination in human behavior. New York: Plenum.

Di Blas, N., Garzotto, F., Paolini, P., \& Sabiescu, A. (2009). Digital storytelling as a whole-class learning activity: lessons from a three-years project. Interactive Storytelling, 14-25. http://dx.doi.org/10.1007/978-3-642-10643-9_5.

Edwards, A., \& D'arcy, C. (2004). Relational agency and disposition in sociocultural accounts of learning to teach. Educational Review, 56(2), 147-155. http://dx.doi.org/10.1080/ 0031910410001693236.

Falloon, G. (2013). Young students using ipads: app design and content influences on their learning pathways. Computers \& Education, 68, 505-521. http://dx.doi.org/10.1016/ j.compedu.2013.06.006.

Guthrie, J. T., \& Wigfield, A. (2000). Engagement and motivation in reading. In M. L. Kamil, P. B. Mosenthal, P. D. Pearson, \& R. Barr (Eds.), Handbook of reading research (Vol. 3; pp. 403-422). New York, NY: Longman.

Hager, E. B. (2010). Ipad opens world to a disabled boy. New York Times. Available at http://www.nytimes.com/2010/10/31/nyregion/31owen.html?_r1/40 Accessed 21.11.10. Harrold, R. (2012). The ipad effect: Leveraging engagement, collaboration, and perseverance. Available at http://www.tieonline.com/view_article.cfm?ArticleID1/4100 Accessed 10.10.12.

Howe, C., \& Mercer, N. (2007). Children's social development, peer interaction and classroom learning. Primary Review Research Survey 2/1b. Cambridge: University of Cambridge.

Hutchison, A., Beschorner, B., \& Schmidt-Crawford, D. (2012). Exploring the use of the ipad for literacy learning. The Reading Teacher, 66(1), 15-23. http://dx.doi.org/10.1002/ TRTR.01090.

Hyun, E., \& Davis, G. (2005). Kindergartners' conversations in a computer-based technology classroom. Communication Education, 54(2), 118-135. http://dx.doi.org/10.1080/ 03634520500213397.

Jacques, R. (1995). Engagement as a design concept for multimedia. Canadian Journal of Educational Communication, 24(1), 49-59.

Kucirkova, N., Messer, D., Sheehy, K., \& Flewitt, R. (2007). Sharing personalised stories on iPads: a close look at one parent-child interaction. Literacy, 47(3), 115-122. http:// dx.doi.org/10.1111/lit.12003.

Levine, M. J. (2012). Reading with young children: Something old and something new? Joan Ganz Cooney Center. http://joanganzcooneycenter.org/Cooney-Center-Blog-270.html Accessed 02.01.13.

Lim, C. P. (2008). Global citizenship education, school curriculum and games: learning mathematics, English and science as a global citizen. Computers \& Education, 51(3), 1073-1093. http://dx.doi.org/10.1016/j.compedu.2007.10.005.

Littleton, K., Mercer, N., Dawes, L., Wegerif, R., Rowe, D., \& Sams, C. (2005). Talking and thinking together at key stage 1. Early Years, 25(2), 167-182. http://dx.doi.org/10.1080/ 09575140500128129.

Lynch, S., Kuipers, J., Pyke, C., \& Szesze, M. (2005). Examining the effects of a highly rated science curriculum unit on diverse students: results from a planning grant. Journal of Research in Science Teaching, 42(8), 912-946. http://dx.doi.org/10.1002/tea.20080.

Manuguerra, M., \& Petocz, P. (2011). Promoting student engagement by integrating new technology into tertiary education: the role of the ipad. Asian Social Science, 7(11), 61- 65. http://dx.doi.org/10.5539/ass.v7n11p61. 
Matthews, J., \& Jessel, J. (1993). Very young children use electronic paint: a study of the beginnings of drawing with traditional media and computer paintbox. Visual Arts Research, 47-62.

Matthews, J., \& Seow, P. (2007). Electronic paint: understanding children's representation through their interactions with digital paint. International Journal of Art \& Design Education, 26(3), 251-263. http://dx.doi.org/10.1111/j.1476-8070.2007.00536.x.

McClanahan, B., Williams, K., Kennedy, E., \& Tate, S. (2012). A breakthrough for Josh: how use of an iPad facilitated reading improvement. TechTrends, 56(3), 20-28. Mercer, N. (1996). The quality of talk in children's collaborative activity in the classroom. Learning and Instruction, 6(4), 359-377.

http://dx.doi.org/10.1016/S0959-4752(96) 00021-7.

Mercer, N. (2000). Words and minds: How we use language to think together. London: Routledge.

Mercer, N., \& Dawes, L. (2001). Dialogues for teaching and learning. In Frank Banks, \& A. Shelton Mayes (Eds.), Early professional development for teachers (pp. 142-158). London: David Fulton in Association with the Open University.

Mercer, N., Dawes, L., \& Staarman, J. K. (2009). Dialogic teaching in the primary science classroom. Language and Education, 23(4), 353-369. http://dx.doi.org/10.1080/ 09500780902954273.

Mercer, N., Wegerif, R., \& Dawes, L. (1999). Children's talk and the development of reasoning in the classroom. British Educational Research Journal, 25(1), 95-111. http:// dx.doi.org/10.1080/0141192990250107.

Milman, N. B., Carlson-Bancroft, A., \& Boogart, A. V. (2012, June 25). Ipads in a prek-4th independent school-year 1-enhancing engagement, collaboration, and differentiation across content areas. In Paper presented at the international society for technology in education conference, San Diego, California.

Osmon, P. (2011). Paperless classrooms: A networked Tablet PC in front of every child. Proceedings of the British Society for Research into Learning Mathematics, 31(2), 55-60. Pai, S. (2012). What's really best for learning?. http://www.commonsensemedia.org/blog/whats-really-best-for-learning Accessed 20.06.13.

Parish-Morris, J., Mahajan, N., Hirsh-Pasek, K., Golinkoff, R. M., \& Collins, M. F. (2013). Once upon a time: parent-child dialogue and storybook reading in the electronic era.

Mind, Brain, and Education, 7(3), 200-211.

Pure Oxygen Labs. (2013). How many apps are in each app store?. Available at http://www.Pureoxygenmobile.Com/how-many-apps-in-each-app-store/\#sthash.Nn5og81r.Dpuf Accessed 05.06.13.

Rojas-Drummond, S., Albarrán, C., \& Littleton, K. (2008). Collaboration, creativity and the co-construction of oral and written texts. Thinking Skills and Creativity, 3(3), 177-191. http://dx.doi.org/10.1016/j.tsc.2008.09.008.

Rojas-Drummond, S., \& Mercer, N. (2003). Scaffolding the development of effective collaboration and learning. International Journal of Educational Research, 39(1), 99-111. http://dx.doi.org/10.1016/S08830355(03)00075-2.

Schmitz, M. J., \& Winskel, H. (2008). Towards effective partnerships in a collaborative problem-solving task. British Journal of Educational Psychology, 78(4), 581-596. http:// dx.doi.org/10.1348/000709908X281619.

Shuler, C. (2012). Ilearn ii: An analysis of the education category on Apple's app store (Vol. 28 (pp. 2012). New York: The Joan Ganz Cooney Centre at Sesame Workshop. Available at http://www.joanganzcooneycenter.org/wp-content/uploads/2012/01/ilearnii.pdf Accessed 02.01.13.

Stamelos, I., Refanidis, I., Katsaros, P., Tsoukias, A., Vlahavas, I., \& Pombortsis, A. (2000). An adaptable framework for educational software evaluation. Recent Developments and Applications in Decision Making, 347-360. http://dx.doi.org/10.1007/978-1-4757-4919-9_23. 
Statista. (2013). Most popular Apple app store categories in January 2013, by share of available apps (in percent). Available at http://www.Statista.Com/statistics/166976/popular-categories-in-the-app-store Accessed 10.06.13.

Tao, P. K. (1999). Conceptual change in science through collaborative learning at the computer. International Journal of Science Education, 21(1), 39-57. http://dx.doi.org/ 10.1080/095006999290822.

Walker, D. (Ed.). (1982/1983, reprinted in 2006). 3. The evaluation of computer-assisted learning. London:

Routledge.

Webb, P., \& Treagust, D. F. (2006). Using exploratory talk to enhance problem-solving and reasoning skills in grade-7 science classrooms. Research in Science Education, 36(4), 381-401. http://dx.doi.org/10.1007/s11165-005-9011-4.

Wegerif, R., \& Mercer, N. (1996). Computers and reasoning through talk in the classroom. Language and Education, 10(1), 47-64. http://dx.doi.org/10.1080/ 09500789608666700.

Wegerif, R., Mercer, N., \& Dawes, L. (1999). From social interaction to individual reasoning: an empirical investigation of a possible socio-cultural model of cognitive development. Learning and Instruction, 9(6), 493-516. http://dx.doi.org/10.1016/S0959-4752(99)00013-4. 